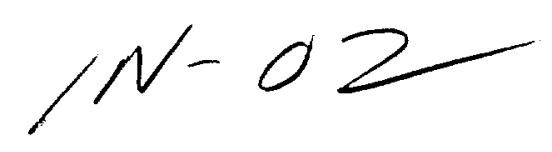

NASA Contractor Report 198544

\title{
Spanwise Spacing Effects on the Initial Structure and Decay of Axial Vortices
}

B.J. Wendt

Modern Technologies Corporation

Middleburg Heights, Ohio

and

B.A. Reichert

Kansas State University

Manhattan, Kansas

November 1996

Prepared for

Lewis Research Center

Under Contract NAS3-27377

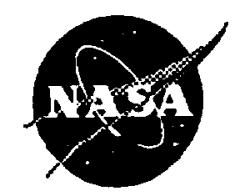

National Aeronautics and

Space Administration 



\title{
SPANWISE SPACING EFFECTS ON THE INITIAL STRUCTURE AND DECAY OF AXIAL VORTICES
}

\author{
B. J. Wendt", \\ Modern Technologies Corporation, Middleburg Heights, Ohio, 44130 \\ B. A. Reichert ${ }^{\ddagger}$ \\ Kansas State University, Manhattan, Kansas, 66506
}

\section{Abstract}

The initial structure and axial decay of an array of streamwise vortices embedded in a turbulent pipe boundary layer is experimentally investigated. The vortices are shed in counter-rotating fashion from an array of equallyspaced symmetric airfoil vortex generators. Vortex structure is quantified in terms of crossplane circulation and peak streamwise vorticity. Flow conditions are subsonic and incompressible. The focus of this study is on the effect of the initial spacing between the parent vortex generators. Arrays with vortex generators spaced at 15 and 30 degrees apart are considered. When the spacing between vortex generators is decreased the circulation and peak vorticity of the shed vortices increases. Analysis indicates this strengthening results from regions of fluid acceleration in the vicinity of the vortex generator array. Decreased spacing between the constituent vortices also produces increased rates of circulation and peak vorticity decay.

\section{Introduction}

The use of surface-mounted vortex generators is now standard practice in a variety of fluids engineering applications where a certain amount of flow conditioning is critical for the proper performance of flow components. Vortex generators are, at the most basic level, a protrusion into a fluid stream that sheds a trailing vortex (or vortices) into the boundary layer downstream. The key to the effectiveness of the vortex generator lies in the convective nature of this shed vortex. Two important mechanisms of "convectiveness" are identified:

1. Mixing. The swirling motion of the fluid in the vortex mixes high energy fluid of the freestream or core flow into the slower moving fluid of the boundary layer. Thus mixing originates with the normal (up and down) component of the crossflow induced by the vortex. In the downflow region of the vortex the boundary layer is thinned and local values of skin friction are correspondingly high. In the upflow

"Research Engineer, 7530 Lucerne Drive, Islander Two, Suite 206, Member AIAA

${ }^{\ddagger}$ Associate Professor, Department of Mechanical Engineering, 302 Durland Hall, Senior Member AIAA

Copyright 1996 by the American Instiune of Aeronauties and Astronsutics, Inc. No copyright is assered in the United States under Titie 17, U.S. Code. The U.S. Government has a royaliy-free license to exercise all rights under the copyright claimed herein for Goveramental purposes. All other rights are reserved by the copyright owner. region, the boundary layer is thickened and local values of skin friction are correspondingly lowered. The overall or integrated effect of vortex mixing is to promote re-energization of the boundary layer fluid and boundary layer attachment. The mixing mechanism of vortex generator effectiveness is long established. It was developed in experimental programs conducted in the 1950s and early-1960s by Grose and Taylor ${ }^{1}$, Schubauer and Spangenburg ${ }^{2}$, Spangler and Wells ${ }^{3}$, and Taylor ${ }^{4}$. Pearcy ${ }^{5}$ summarizes much of the early work conducted on vortex generator use.

2. Secondary flow control. The rotational orientation of the vortex may also be used to counter boundary layer thickening due to the cumulative convective effects of secondary flows. This problem is typically encountered in the ducted components of the aircraft propulsion system. Here the control mechanism originates with both the normal and transverse (left and right) components of the crossflow induced by the vortex. Recent experimental work in diffusing S-ducts ${ }^{6,7}$ have demonstrated the effectiveness of applying vortex generators to control secondary flows.

Since the vortex generator is an obstruction projecting into the fiuid stream there is a drag penalty or loss of flow momentum resulting from its use. The goal of designing fluid components with vortex generators is thus one of maximizing component performance through one or both mechanisms of flow control described above, while minimizing the number of devices used. This optimization process presents practical difficulties due to the large number of parameters involved in a general

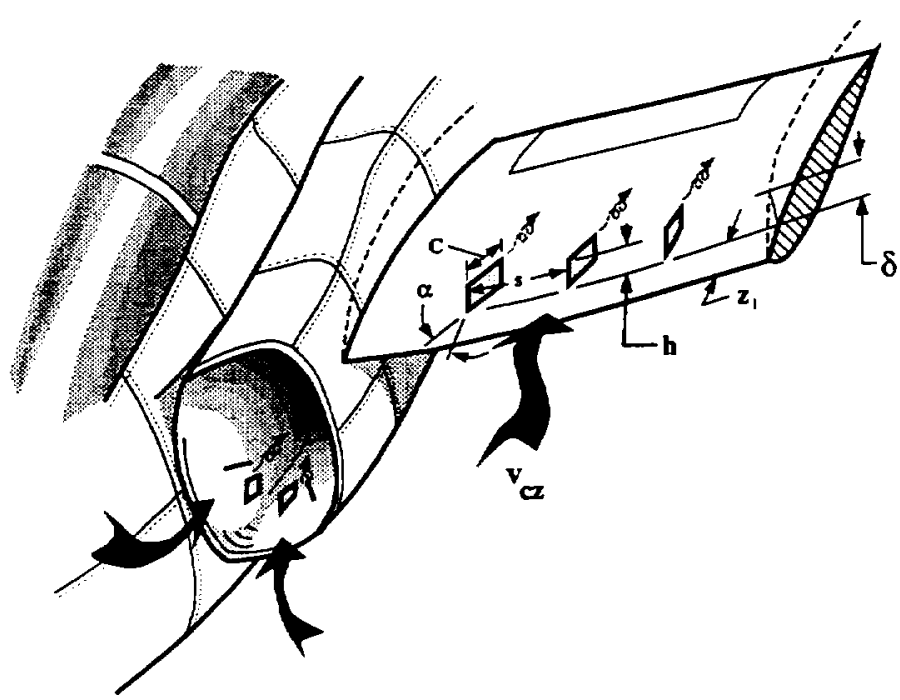

Figure 1 Flow conditioning with vortex generators. 
configuration of vortex generators. Consider Figure 1 which illustrates an array of vane-type vortex generators in use on the wing surface of an aircraft. First we must consider the geometric aspects of the individual vortex generators. These include chordlength, $c$, span, $h$, angleof-attack with respect to the freestream direction, $\alpha$, and other parameters related to the vane cross-section and axial profile. Secondly we also need to consider the geometry of the array formation. This would include the spacing, $s$, between the individual elements in the array, the axial location of the array, $z_{l}$, on the wing, and the rotational nature of the array, i.e. whether the vortices are shed counter or co-rotating with respect to immediate neighbors. Finally, the flow conditions impinging on the array (freestream Mach number, Reynolds number, and boundary layer thickness for example) round out our list. Limited experimental parametric studies have been conducted to develop effective strategies for vortex generator use in the subsonic diffuser flows described in References 6, 8, and 9. Of greater potential utility is the application of computational fluid dynamics to the optimization problem. In particular, fast component design codes based on solutions to the parabolized (or "reduced") Navier-Stokes equations have the ability to run through large parametric ranges in a time and cost effective manner. In the one notable example developed at NASA-Lewis, a code known as RNS3D (a modification of the PEPSIG RNS code based on the stream functionvorticity formulation of the Navier-Stokes equations and developed for internal flows on nonorthogonal grids by Levy, Briley, and McDonald ${ }^{10}$ ) has recently been used to optimize vortex generator use in a Defense Research Agency (DRA)-designed diffusing S-duct. Test data obtained at DRA verify the remarkable reductions in total pressure distortion predicted by the code.?

In these design codes vortex generators are not modelled as a part of the flow surface geometry of the duct but are represented by modelling the effects of the shed vortices on the flowfield. The mathematical models used are typically exponential equations representing the convective and wake properties induced by the vortex gen-

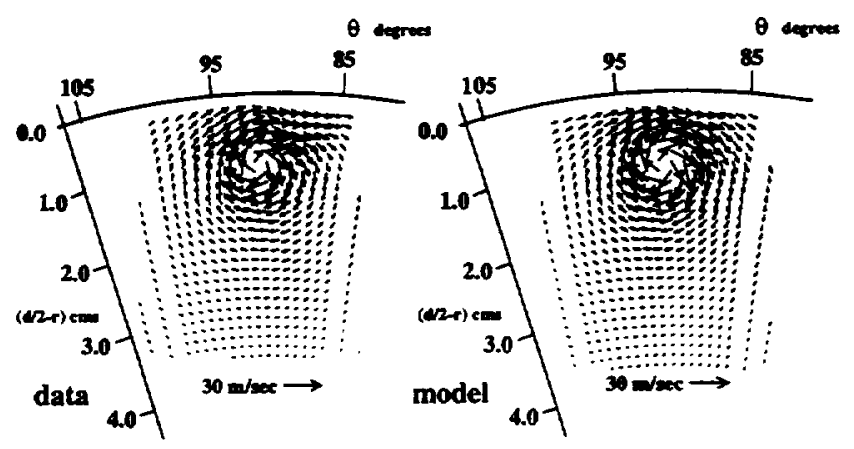

Figure 2 A comparison of the transverse velocity field of an embedded vortex; data on the left, and a model constructed from the superposition of Oseen vortices on the right. erator. These models are essentially boundary conditions on the velocity or vorticity fields applied at an axial location representative of the physical location of the vortex generators (typically at the trailing edge tip). This vortex generator modelling process consists of two distinct parts.

In the first part a model of the convective and wake effects of the shed vortex or vortex array is constructed. To demonstrate how the model represents the convective nature of the vortex, consider Figure 2, which illustrates the secondary velocity field of an embedded vortex (data on the left, model on the right) shed from an airfoiltype vortex generator. This vortex generator is one of 12 symmetrically placed vortex generators spanning the full inside circumference of a straight pipe. The data is acquired in the crossplane one chordlength downstream of the vortex generator trailing edges. The model flowfield is constructed from from a summation of 24 terms (12 embedded vortices plus 12 image vortices to represent the convective influence of the wall) with each term having the form ${ }^{11}$ :

$$
\Gamma_{i}\left[1-\exp \left(\frac{-\pi \omega_{i}^{\max }}{\Gamma_{i}}\right) R_{i}^{2}\right]
$$

where $\Gamma_{i}$ is the measured circulation of the $i$ th vortex or its corresponding image, $\omega_{i}^{\max }$ is the measured peak or maximum value of the induced streamwise vorticity field, and $R_{i}$ is the crossplane distance from the measured location of the vortex center. These quantities are known as "vortex descriptors" following the work of Westphal et al. ${ }^{12}$ The model in Eq. (1) is based on the classical "ideal viscous" or Oseen vortex. ${ }^{13}$ Other suitable models include potential vortices and Rankine vortices." Experimental workers concerned with embedded vortices have often noticed the close similarity of observed crossplane vortex structure to these simple two-dimensional models. Potential vortices were first applied to results obtained in subsonic diffuser studies by Grose and Taylor. ${ }^{1}$ Later, Pearcy ${ }^{5}$ would develop embedded vortex interaction models based on the inviscid representation of embedded vortex structure. Eibeck and Eaton ${ }^{14}$ compared the structure of a single embedded vortex to that of a Rankine vortex. Studies by Pauley and Eaton ${ }^{15}$ and Wendt et al. ${ }^{11,13,16}$ have made comparisons to the Oseen model. To properly represent the flow losses induced by the use of vortex generators a model similar to that described above is used to mimic the axial velocity deficit or wake downstream of the vortex generator. An example is the following relation developed by Kim and Patel ${ }^{17}$ :

$$
v_{z}=v_{c z}-\Delta v_{z i}^{\max } \exp \left(-\ln 2\left\{\frac{r}{R_{e i}}\right\}^{2}\right)
$$

The patchwork Rankine model uses the vortex viscous core radius, $R_{c i}$, as a measure of vortex concentration. Peak vorticity, circulation, and viscous core radius are simply related: $R_{c i}^{2}=\Gamma_{i} /\left(\pi \omega_{i}^{\max }\right)$. 


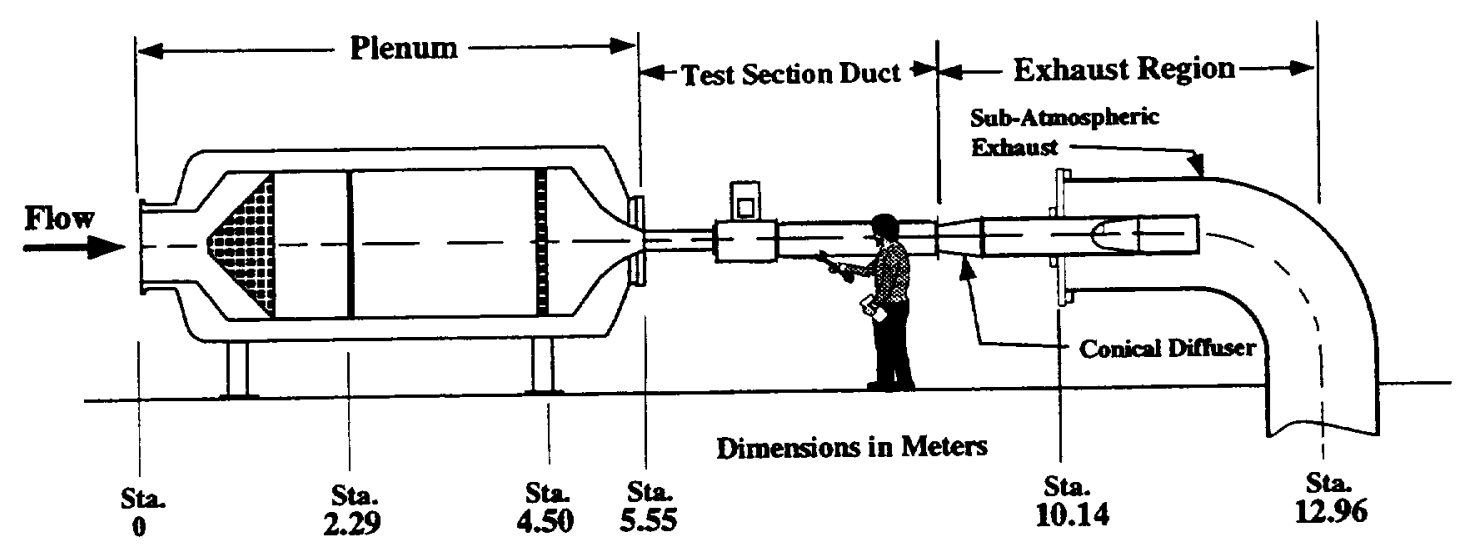

Figure 3 The Internal Fluid Mechanics Facility of NASA Lewis.

where $v_{z}$ is the primary or axial component of velocity, $v_{e z}$ is the freestream value of axial velocity, $\Delta v_{z i}^{m a x}$ is the maximum axial velocity defect measured at the center of the viscous core of the vortex, and $R_{c i}$ is the previously noted core radius of the Rankine model.

In the second part of the modelling process we relate the descriptors of the shed or modelled vortex to the collection of parameters illustrated in Figure 1, or in other words, define the following functional relationships:

$$
\begin{aligned}
\Gamma & =\Gamma(z, c, h, \alpha, \text { profile, } s, \delta, M, R e, \ldots), \\
\omega^{\max } & =\omega^{\max }(z, c, h, \alpha, \text { profile, } s, \delta, M, R e, \ldots), \\
R & =R(z, c, h, \alpha, \text { profile, } s, \delta, M, R e, \ldots), \\
\Delta v_{z}^{\max } & =\Delta v_{z}^{\max }(z, c, h, \alpha, \text { profile }, s, \delta, M, R e, \ldots),
\end{aligned}
$$

where "profile" refers to the shape or type of vortex generator, $M$ is the freestream or core Mach number of the flow, and $R e$ is a Reynolds number.

In this experimental program the relationships in Eq. (3) are studied for one type of vortex generator (NACA 0012). The vortex generators are mounted on the inside surface of a straight pipe, either in isolation or in counterrotating arrays. Pipe core flow conditions are subsonic with a nominal turbulent boundary layer thickness to pipe diameter ratio, $\delta / d=0.09$. Three-dimensional mean flow velocity data are acquired in crossplane grids located at regular axial intervals downstream of the vortex generator or vortex generator array. This is done using a rake of seven-hole probes.

Previous reports have considered the influence of vortex generator geometry and axial decay behavior. The initial vortex structure and decay of an array of counterrotating vortices shed from a symmetric arrangement of vortex generators was described in Reference 11. The influence of vortex generator geometry and the axial decay of an isolated vortex was the focus of Reference 18. During the course of these studies it became apparent that the spacing between the vortex generators had a strong influence on the initial structure of the shed vortices. The primary objective of this paper is to consider the effect of vortex generator spacing on the shed vortex descriptors and subsequent axial decay. This is done by mounting the vortex generators at an $s$ value which is half of that reported in Reference 11. The results reported here are compared against similar results in References 11 and 18.

\section{Facilities and Procedures}

This study was conducted in the Internal Fluid Mechanics Facility (IFMF) of NASA Lewis. This subsonic facility, as it was configured for this test, is illustrated in Figure 3. Atmospheric air is supplied from the surrounding test cell to a large settling plenum equipped with honeycomb flow straighteners and screens. Upon leaving the plenum the airstream is accelerated through an axisymmetric contraction and into the test section duct. The test section duct consists of a straight circular pipe of inside diameter $d=20.4 \mathrm{cms}$. Driving this flow is a downstream sub-atmospheric exhaust chamber which is continuously evacuated by central air supply compressors. The Mach number range in the test section is between 0.2 and 0.8 with corresponding Reynolds numbers (based on test section diameter) between 0.95 and 3.80 million. Mass flow rates are between 3 and $7 \mathrm{kgs} / \mathrm{sec}$. More information on the design and operation of the IFMF may be found in the report of Porro et al. ${ }^{19}$

Figure 4 is a cut-away sketch of the test section duct. A short section of straight pipe (labelled "inlet pipe" in Figure 4) connects the exit of the facility plenum contraction to the duct segment containing the vortex generator array. Static pressure taps located on the surface of the inlet pipe allow the nominal core Mach number in the test section to be set and monitored.

The test section segment containing the vortex generator array is referred to as the "vortex generator duct". The inside surface of the vortex generator duct (and hence the attached vortex generator array) rotates about an axis coinciding with the test section centerline. 360 degrees of rotation is possible. The rotation is driven by a motor and gear located in an airtight box above the vortex generator duct.

The vortex generator is illustrated in Figure 5. These models consist of a NACA 0012 airfoil-shaped blade 


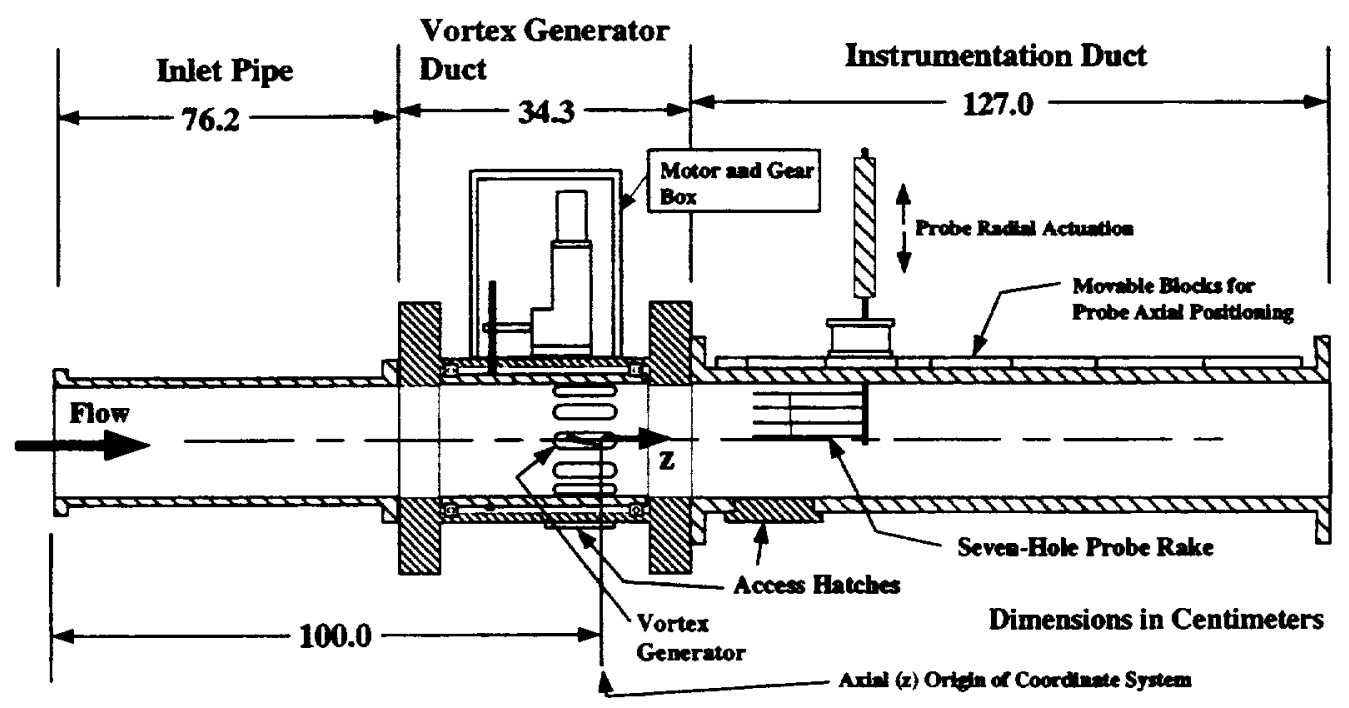

Figure 4 A cut-away sketch of the test section duct.

mounted perpendicular to the surface of a base plug. The surface of the base plug is contoured to the inside radius of the vortex generator duct. Both blade and plug are machined from an aluminum alloy.

The cylindrical coordinate system used in this study originates in the vortex generator duct. $z=0$ coincides with the trailing edges of the vortex generator array. The axial location of downstream $(r, \theta)$ crossplanes is given in terms of blade chord. For example, the first survey location possible is the $(r, \theta)$ crossplane located at $z=0.38 c$.

The test section segment downstream of the vortex generator duct is non-rotating. This duct segment is labelled "instrumentation duct" in Figure 4. The flowfield measurements are acquired in this duct through the use of a radially actuated rake-probe indicated in Figure 4. To acquire data in an $(r, \theta)$ crossplane, the rake-probe is first actuated over a radial segment extending from the duct wall to the duct centerline. The vortex generator duct and vortex generator array are then rotated an increment in circumferential position, $\Delta \theta$, and the radial survey re-

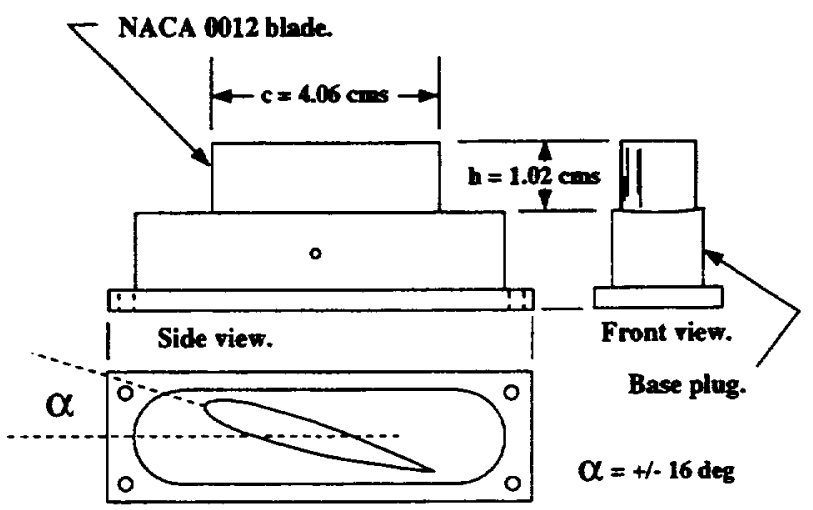

Top view.

Figure 5 The airfoil vortex generator. peated. In this fashion, pie-shaped pieces of the flowfield are examined. A narrow slot running the approximate length of the instrumentation duct allows the rake-probe to be located at various downstream crossplanes. A set of slot-sealing blocks determines the allowable axial location of survey crossplanes, $z_{i}$ :

$$
\begin{gathered}
z_{i}=0.38 c, 1.00 c, \ldots, 10.38 c \\
14.75 c, 15.38 c, \ldots, 24.75 c
\end{gathered}
$$

The rake-probe consists of 4 seven-hole probe tips spaced $2.54 \mathrm{cms}$ apart. These probes are calibrated in accordance with the procedure outlined by Zilliac. ${ }^{20}$ The flow angle range covered in calibration is $\pm 60^{\circ}$ in both pitch and yaw for the probe tip closest to the wall. The calibration range for the outer 3 tips is approximately $\pm 30^{\circ}$. Uncertainty in flow angle measurement is $\pm 0.7^{\circ}$ in either pitch or yaw, for flow angle magnitude below 35 degrees (pitch and yaw flow angle magnitude did not exceed 35 degrees in this study). The corresponding uncertainty in velocity magnitude is approximately $\pm 1 \%$ of the core velocity, $v_{c z}$. 


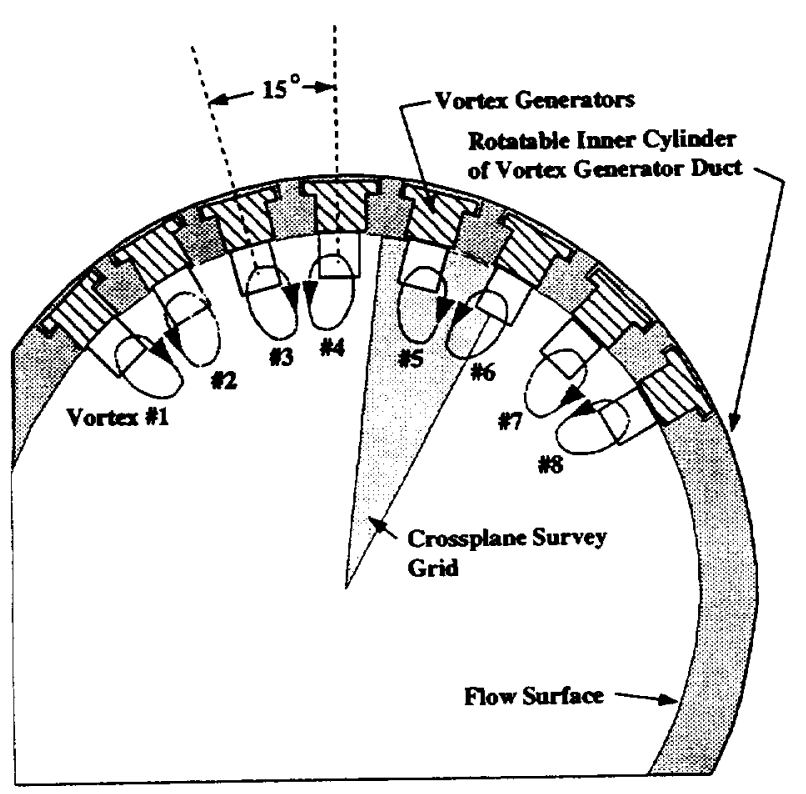

Figure 6 The vortex generator array.

Figure 6 is a crossplane view of the duct (looking upstream) showing the array of vortex generators. The vortex generators are equally spaced circumferentially at mid-chord. $\Delta \theta_{b}$ between the mid-chord position of adjacent blades is $15^{\circ}$. Each vortex in this array has a "domain-of-influence" in the crossplane. The circumferential extent of this domain is defined by the behavior of the circumferential velocity component, $v_{\theta}$, near the wall. For the interior vortex number 5 in Figure 6, for example, the flow near the wall and above the core of the vortex is moving clockwise ( $v_{\theta}$ negative). The flow above neighboring vortex core no. 6 is moving counter-clockwise ( $v_{\theta}$ positive). Between these two vortex cores $v_{\theta}$ vanishes along a roughly radial line. The location where this line intersects the wall is referred to as a "stagnation point" in $v_{\theta}$. The circumferential extent of no. 5's domain thus lies between the stagnation points in $v_{\theta}$ and is about equal to the spacing between vortex generators, i.e. about $15^{\circ}$, although this increases somewhat as the array develops downstream. The circumferential extent of the survey grid in this study is meant to capture the full domain-of-influence of one vortex thereby isolating the viscous core and allowing the vortex descriptors to be evaluated. The survey grid is between 20 and 35 degrees in extent and captures all of vortex no. 5 as shown by the shaded area in Figure 6 . Note that a portion of vortex no. 6 (and, to a smaller extent, no. 4) is also captured.

As discussed in References 11 and 18 crossplane grid resolution is dependent on the size of the viscous core. For axial locations upstream of the $z=6$ chord crossplane, $\Delta \theta=1^{\circ}$ and $\Delta r=1.3 \mathrm{~mm}$ is sufficient for an accurate assessment of circulation and peak vorticity. For $z>6$ chords, $\Delta \theta=1.5^{\circ}$ and $\Delta r=1.7 \mathrm{~mm}$ is sufficient.

\section{Experimental Results}

Table 1 and Figures 7a-h summarize the results of this study. Table 1 lists the test conditions and derived vortex descriptors for each crossplane illustrated in Figure 7. In the crossplane plots of Figure 7 the radial axis represents distance from the wall, in centimeters, and the circumferential axis represents angular position in degrees. The axial position of each crossplane is listed in units of vortex generator chordlength. The vortex descriptors (for vortex number 5) are listed below each set of crossplane plots in Figures 7a-h.

The vortex descriptors originate from the transverse velocity data in the crossplane. The vector plots on the left-hand side of Figures 7a-h are the measured transverse velocity data. The transverse velocity data is first converted to streamwise vorticity data following the relation:

$$
\omega_{z}=\frac{\delta v_{\theta}}{\delta r}+\frac{v_{\theta}}{r}-\frac{1}{r} \frac{\delta v_{r}}{\delta \theta},
$$

where $\left(v_{r}, v_{\theta}\right)$ are the transverse components of velocity in the radial and circumferential coordinates, respectively. Finite difference formulas are used to represent the spatial derivatives in Eq. (5). The resulting streamwise vorticity fields are plotted on the right-hand side in Figure 7. Solid and dashed contour lines represent negative and positive vorticity, respectively. The contour increment for lines not labelled is $\pm 3000 \mathrm{sec}^{-1}$. $\omega^{\max }$ is located at some grid point having coordinates $\left(r_{c}, \theta_{c}\right)$. The vortex circulation is calculated by first isolating the region of core vorticity in the data field. This is done by referring to

\begin{tabular}{|c|c|c|c|c|}
\hline$\underset{\operatorname{deg}}{\Delta \theta_{b}}$ & $\begin{array}{l}\left(r_{c}, \theta_{c}\right) \\
\text { cms, deg }\end{array}$ & $\begin{array}{c}\mathrm{z} \\
\text { chordlengths }\end{array}$ & $\begin{array}{c}\text { circulation } \\
\mathrm{m}^{2} / \mathrm{sec}\end{array}$ & $\begin{array}{c}\text { peak vorticity } \\
\sec ^{-1}\end{array}$ \\
\hline \multicolumn{5}{|c|}{ Axial Decay of the Narrowly-Spaced Vortex Array } \\
\hline 15 & $(9.3,70)$ & 1.600 & -0.893 & -41752 \\
\hline 15 & $(9.2,69)$ & 1.625 & -0.859 & -38894 \\
\hline 15 & $(9.1,69)$ & 2.250 & -0.830 & -36712 \\
\hline 15 & $(8.7,69)$ & 3.500 & -0.756 & -26869 \\
\hline 15 & $(8.4,69)$ & 4.750 & -0.671 & -16763 \\
\hline 15 & $(8.1,70)$ & 6.000 & -0.598 & -10161 \\
\hline 15 & (7.9,71) & 8.500 & -0.457 & -3856 \\
\hline 15 & $(7.6,71)$ & 10.375 & -0.338 & .2329 \\
\hline \multicolumn{5}{|c|}{ Initial Structure of the Widely Spaced Vortex Array } \\
\hline 30 & $(9.3,92)$ & 1.000 & \multirow[t]{2}{*}{-0.722} & \multirow[t]{2}{*}{-35714} \\
\hline \multicolumn{3}{|c|}{ Initial Structure of the Loolated Vortex } & & \\
\hline$-\cdots$ & $(9.391)$ & 1.000 & -0.643 & .33189 \\
\hline \multicolumn{5}{|c|}{ Uncertainty } \\
\hline & $\pm(0.04,0.3)$ & $\cdots$ & \pm 0.009 & $\pm \mathbf{3 0 0}$ \\
\hline \multicolumn{5}{|c|}{$\begin{array}{l}\text { Notes: } \\
\text { 1. Descriptors for narrowly-spaced array are for vortex \#5. } \\
2 \text { See Figure } 5 \text { for the geometry of the vortex generator. } \\
\text { 3. Core velocity }=81 \mathrm{~m} / \mathrm{sec} \text {, boundary layer thickness }(a t \mathrm{z}=0)=1.78 \mathrm{cms} \\
\text { 4. Crossplane location of vortex generator trailing edge tip (for vortex } \\
\text { generator shedding vortex } \# 5): r_{0}=9.2 \mathrm{cms}, \theta_{0}=70 \text { deg. }\end{array}$} \\
\hline
\end{tabular}

Table 1 - A summary of test conditions and results. 
the contour plots of vorticity in Figure 7. A path enclosing the region of core vorticity is defined. The outer boundary of the core is taken to be the location where streamwise vorticity is $1 \%$ of $\omega^{\text {max }}$. The circulation is then calculated according to:

$$
\oint v \cdot d l,
$$

where $\mathrm{V}$ is the velocity vector in the crossplane and 1 refers to the path coordinate. By using closed paths composed of line segments in the $r$ or $\theta$ coordinate directions the circulation is easily determined. Ur rtainty estimates for all vortex descriptors are given in Table 1. These are derived by combining the uncertainties in measured velocities and probe location in accordance with the procedure outlined by Moffat. ${ }^{21}$

Tive interaction between the vortex and the turbulent pipe boundary layer is depicted with contour plots of primary velocity ratio, $v_{z} / v_{c z}$. These are the middle plots in Figure 7. $v_{c z}$ is the core velocity of the pipe and is listed in Table 1 . The crossplane profile of the vortex generator is indicated by the shading in the plot of streamwise vorticity on Figure $7 \mathrm{~h}$. The comer marked with the dashed cruciform is the trailing edge tip.

a) $z=1.00 \mathrm{c}$

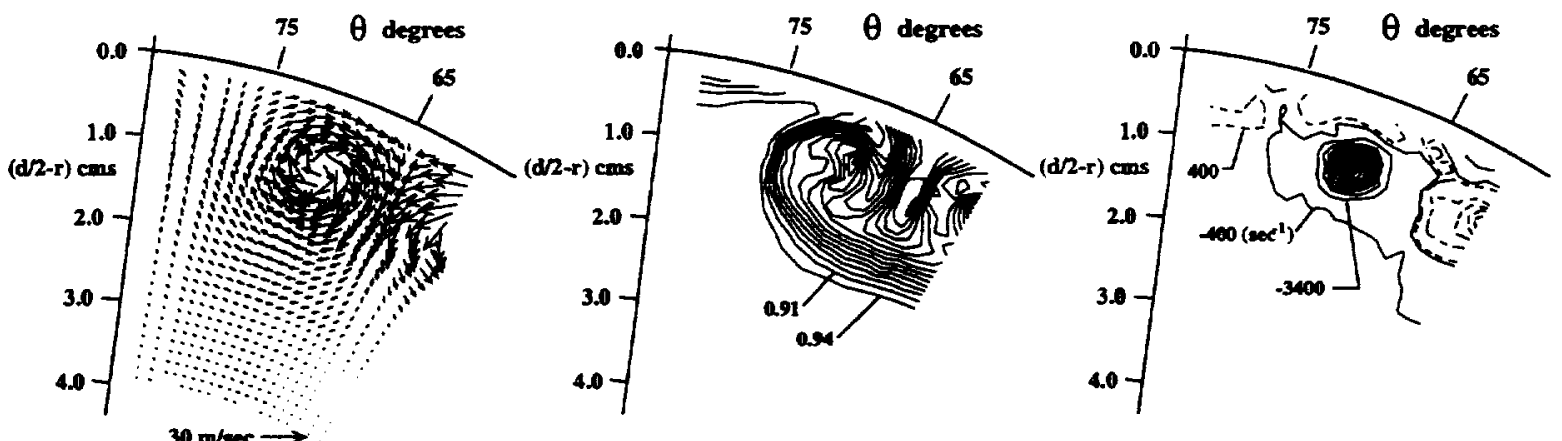

Center of Vortex: $r=9.3 \mathrm{cms}$, theta $=70 \mathrm{deg}$, Circulation $=-0.89 \mathrm{~m} 2 / \mathrm{sec}$, Peak Vorticity $=-41752(1 / \mathrm{sec})$

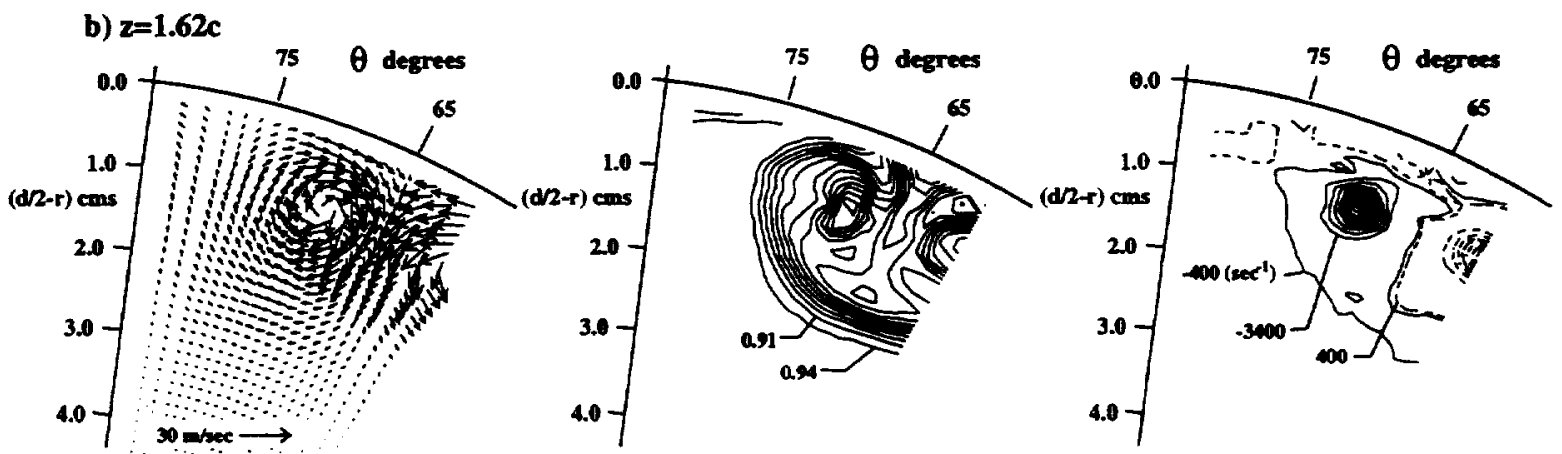

Center of Vortex: $r=9.2 \mathrm{cms}$, theta $=69 \mathrm{deg}$, Circulation $=-0.86 \mathrm{~m} 2 / \mathrm{sec}$, Peak Vorticity $=-38894(1 / \mathrm{sec})$

c) $\mathrm{z}=2.25 \mathrm{c}$

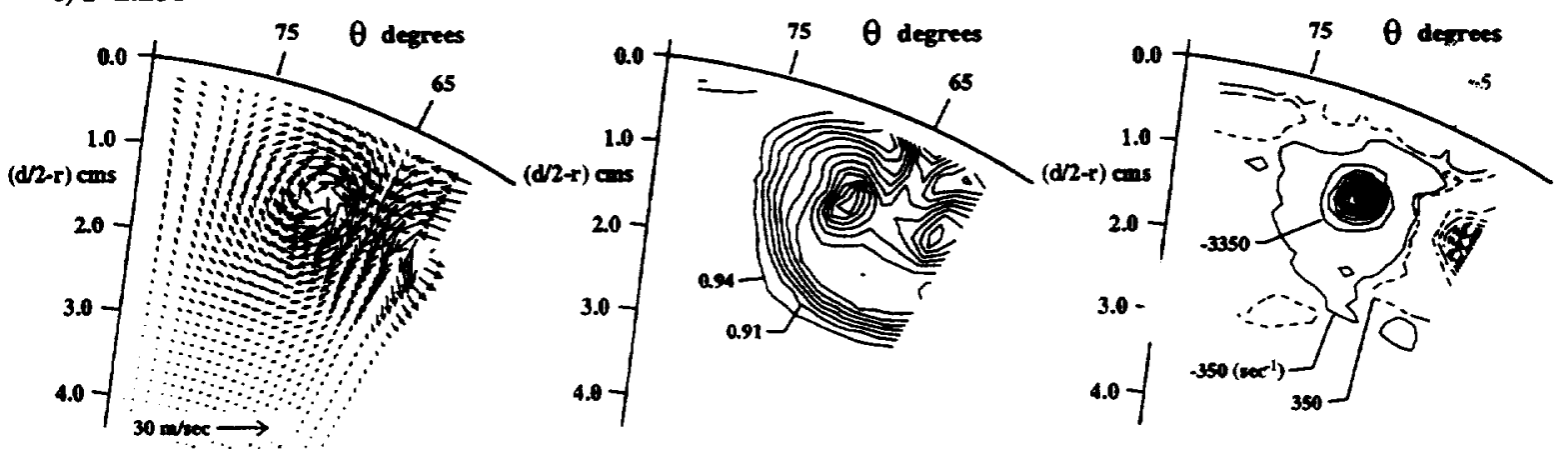

Center of Vortex: $r=9.1 \mathrm{cms}$, theta $=69 \mathrm{deg}$, Circulation $=-0.83 \mathrm{~m} 2 / \mathrm{sec}$, Peak Vorticity $=-36712(1 / \mathrm{sec})$

Figure 7 Velocity and streamwise vorticity results. (Contin ...) 


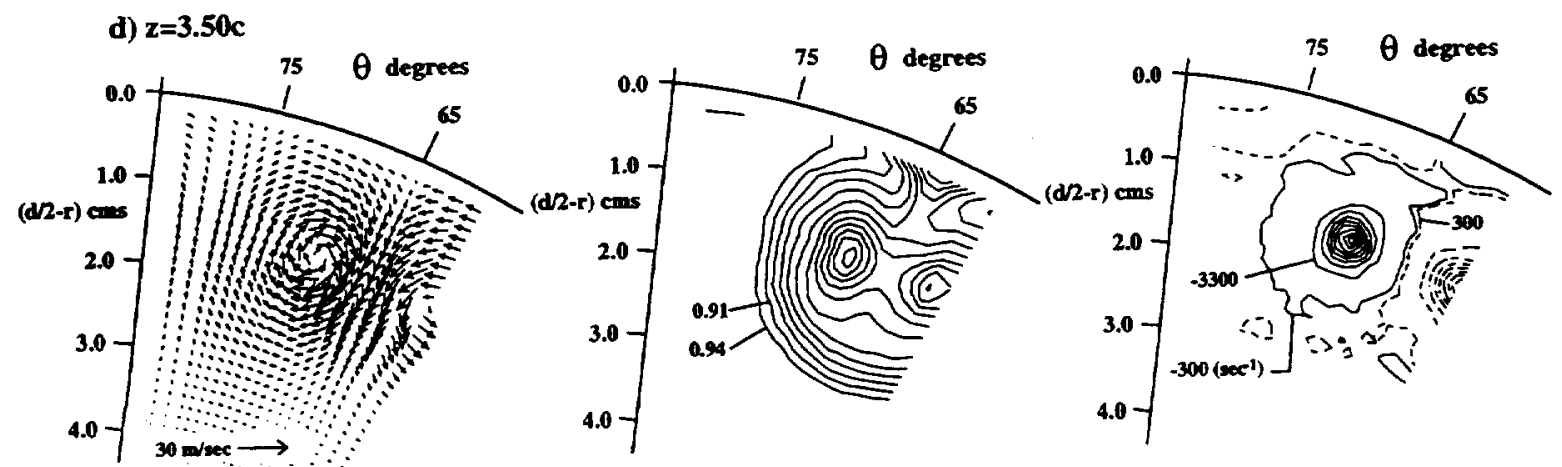

Center of Vortex: $r=8.7 \mathrm{cms}$, theta $=69 \mathrm{deg}$, Circulation $=-0.76 \mathrm{~m} 2 / \mathrm{sec}$, Peak Vorticity $=-26869(1 / \mathrm{sec})$

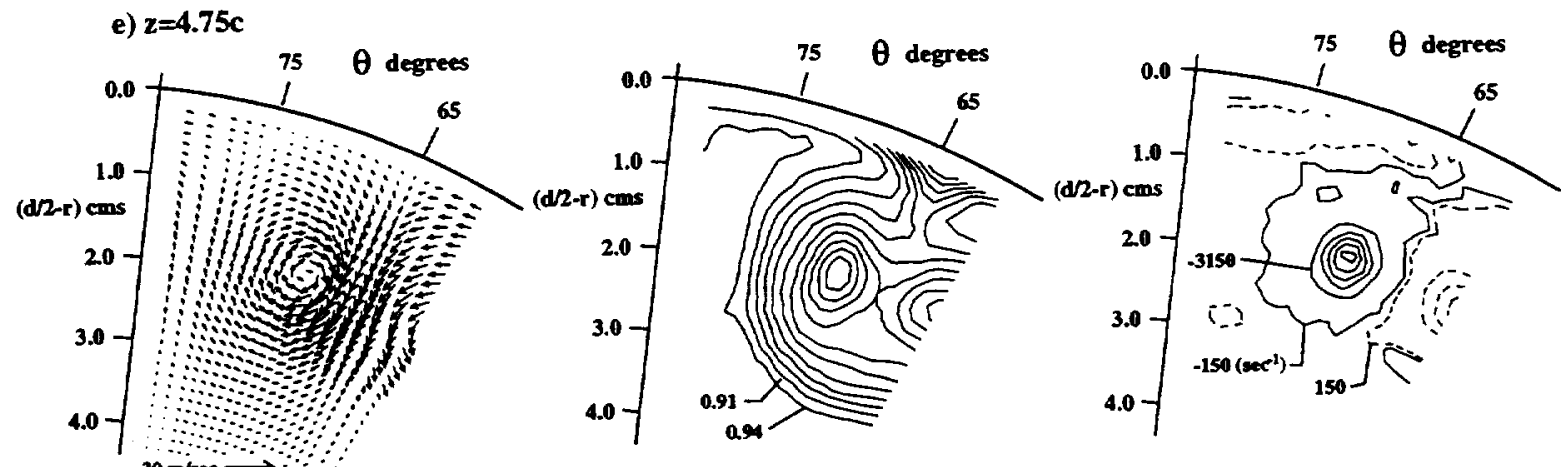

Center of Vortex: $r=8.4 \mathrm{cms}$, theta $=69 \mathrm{deg}$, Circulation $=-0.67 \mathrm{~m} 2 / \mathrm{sec}$, Peak Vorticity $=-16763(1 / \mathrm{sec})$
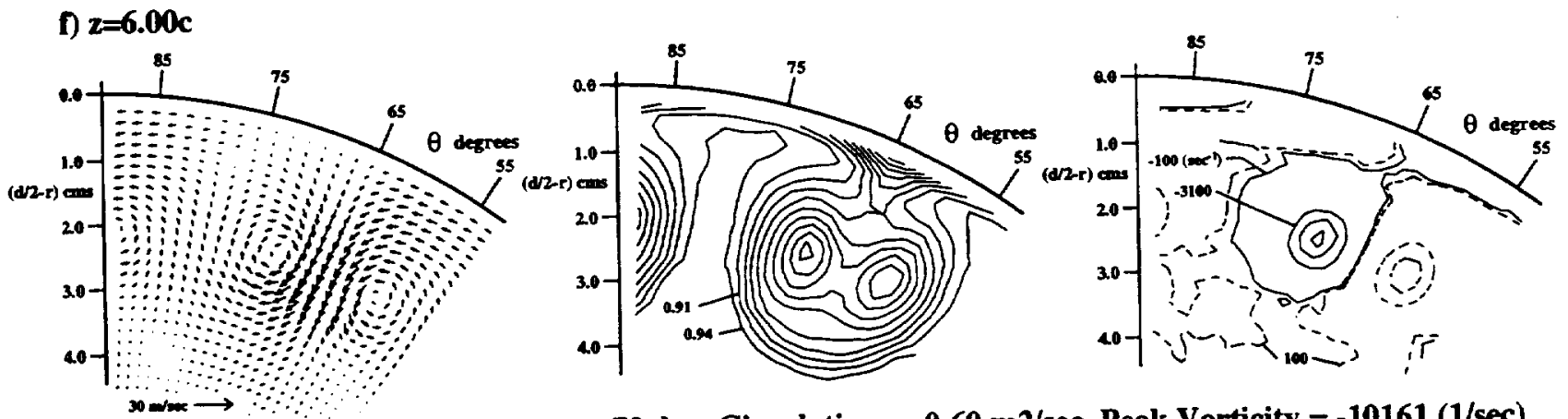

Center of Vortex: $r=8.1 \mathrm{cms}$, theta $=70 \mathrm{deg}$, Circulation $=-0.60 \mathrm{~m} 2 / \mathrm{sec}$, Peak Vorticity $=-10161(1 / \mathrm{sec})$

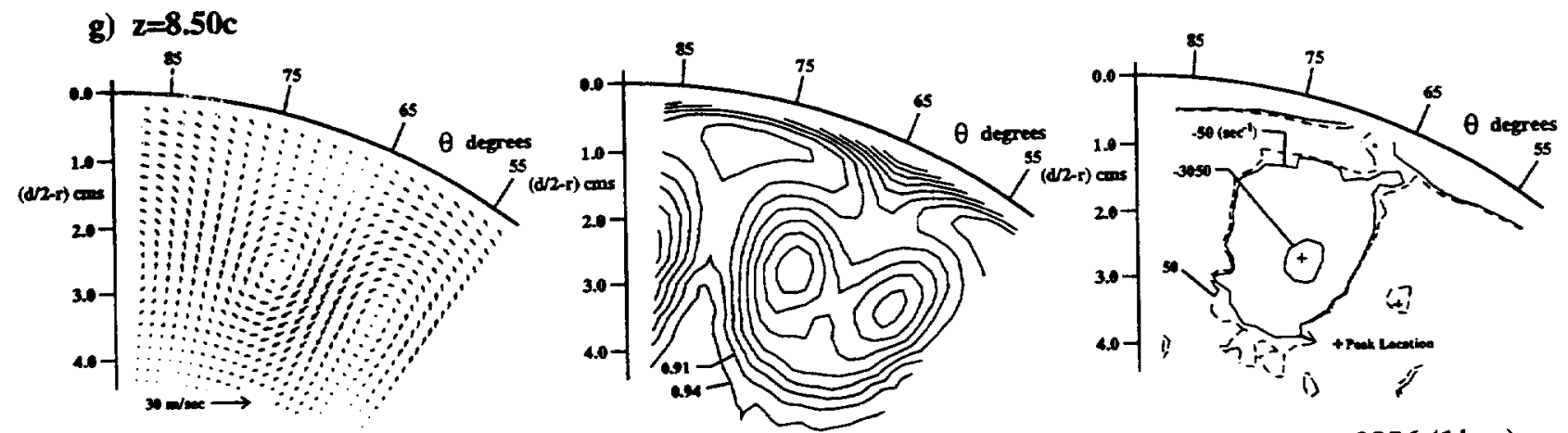

Center of Vortex: $r=7.9 \mathrm{cms}$, theta $=71 \mathrm{deg}$, Circulation $=-0.46 \mathrm{~m} 2 / \mathrm{sec}$, Peak Vorticity $=-3856(1 / \mathrm{sec})$

Figure 7 Velocity and streamwise vorticity results. (Continued ...) 


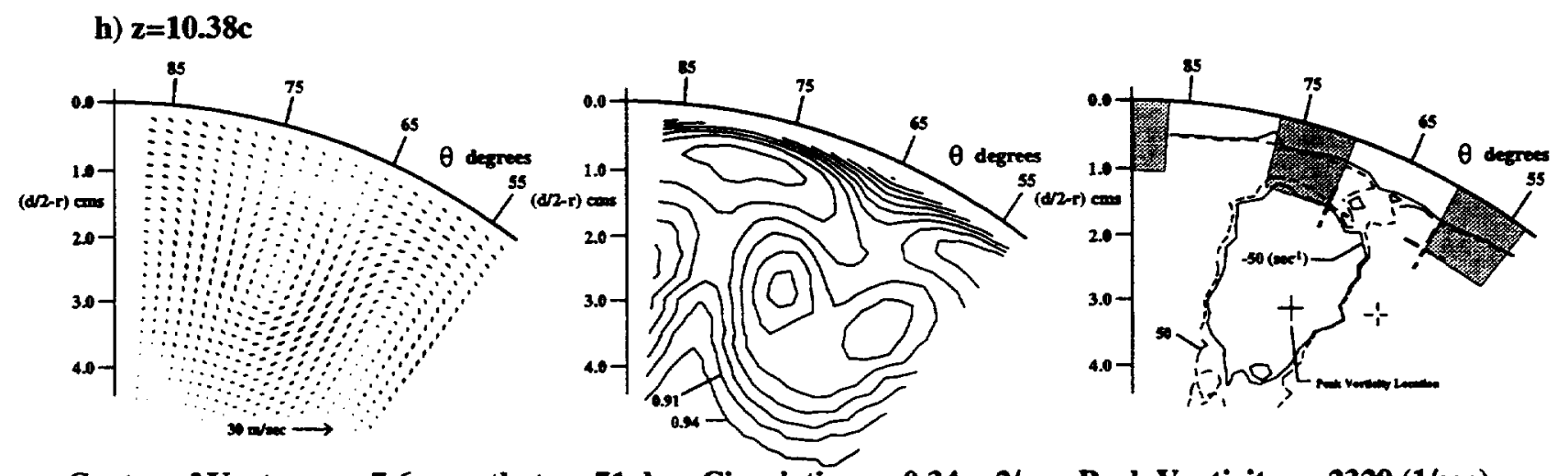

Center of Vortex: $r=7.6 \mathrm{cms}$, theta $=71 \mathrm{deg}$, Circulation $=-\mathbf{0 . 3 4} \mathrm{m} 2 / \mathrm{sec}$, Peak Vorticity $=-\mathbf{2 3 2 9}(1 / \mathrm{sec})$

Figure 7 Velocity and streamwise vorticity results.

\section{Vortex Structure at $z=1$ Chord}

For reference purposes Table 1 contains vortex descriptors derived from two additional test cases not illustrated here. The descriptors of a vortex shed from a single vortex generator (referred to below as the "isolated vortex" test case) are from results detailed in Reference 18. Also listed are descriptors of a vortex contained within an array of 12 counter-rotating vortices. These vortices were shed from vortex generators having an initial spacing $s=\Delta \theta_{b}=30^{\circ}$. The vortex generators in this array thus spanned the interior circumference of the test section. This array formation is termed "widely-spaced". The initial structure and development of the widely-spaced array is detailed in Reference 11.

The axial position at $z=1.000$ chord is our reference crossplane due to the observation (from the widelyspaced array results) that the axial profile of $\omega^{\text {max }}$ peaks here. Figure $7 \mathrm{a}$ illustrates the measured domain of vortex no. 5 at $z / c=1.000$. Vortex 5 is in close proximity to its near-neighbor, vortex 6 , and the two counter-rotating vortices form an "upflow pair", i.e. the flow between vortices is directed away from the wall. The transverse secondary velocities are strongest in the radial coordinate in the region between the vortex cores. This differs from the structure observed for both isolated and widely-spaced array test cases where the strongest transverse velocity is circumferential and exists between the core and wall at $z / c=1.000$.

The circulation results listed in Table 1 show that the shed vortices strengthen as the spacing between vortex generators is decreased. We believe this strengthening results from localized areas of flow accelerating and decelerating through and about the blockage created by the vortex generator array. A brief analysis is given below to support this statement.

It is also interesting to note that $\omega^{\max } \sim \Gamma$ at $z / c=1.000$ for all three spacing test cases. In fact, in all parametric variations considered in this program ${ }^{11}, 18$ (with the exception of vortex generator aspect ratio) circulation and peak vorticity are related in this manner.
Figure 8 illustrates this for all descriptor data obtained at $z / c=1.000$ and airfoil aspect ratio $=8 h / \pi c=2 / \pi$. From a modelling standpoint, the as-of-yet unexplained relationship between $\omega^{\max }$ and $\Gamma$ for variation in aspect ratio is of critical importance. If it is possible to replace an initial $z$ value of $\omega^{\max }$ with a relationship involving $\Gamma$ only, for example, the vortex generator modelling procedure (see Eq. 1) would be greatly simplified.

\section{Axial Decay}

Figures 9a-b illustrate the axial descriptor decay of the isolated vortex, the widely-spaced array, and the narrowly-spaced array vorticies. Figure $9 \mathrm{a}$ illustrates the decay of $\Gamma$, and Figure $9 b$ the decay in $\omega^{\max }$. In general terms, circulation decay is gradual and has a linear profile while, in contrast, the axial decay of peak vorticity is rapid and exponential in profile.

The amount of descriptor decay suffered by the narrowly-spaced array far outstrips the decay exhibited by the isolated vortex and widely-spaced array vorticies. An examination of Figures 7a-h suggests why this is so. Throughout its axial range of development the narrowlyspaced array vortex no. 5 maintains close proximity to

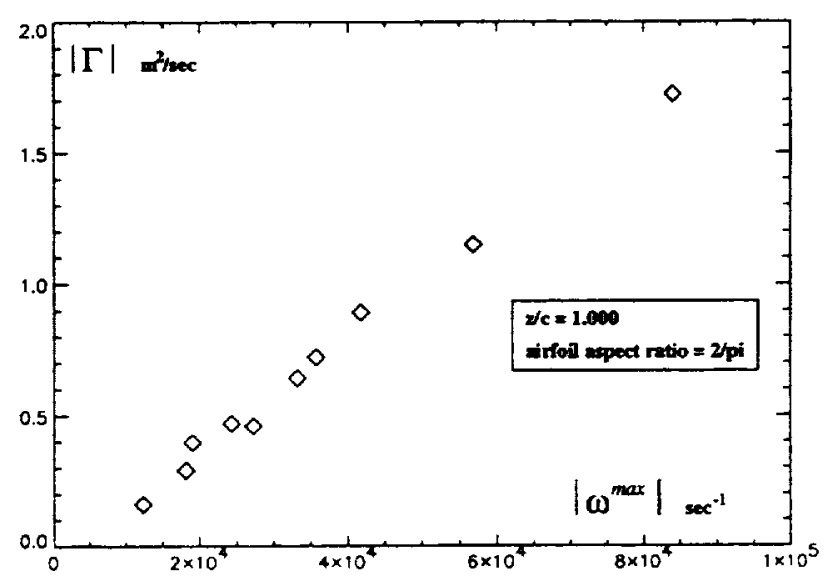

Figure 8 Circulation versus peak vorticity. 
its upflow partner. Contours of streamwise vorticity indicale that the vortex viscous cores are "in contact" for all crossplanes examined. For crossplanes downstream of $z / c=6.000$ viscous core contact occurs between vortices in downflow pairs as well. Thus we suspect descriptor decay by vorticity diffusion to be the dominant decay mecharysm. This decay mechanism has been postulated in a previous study of tightly-spaced arrays of axial vorticies. ${ }^{22}$ It was noted in Reference 22 that the decay rate of the descriptors was proportional to the radial gradient in streamwise vorticity at the crossplane location where the streamwise vorticity is zero (there will always be such a location between two counter-rotating vortex cores). The magnitude of this gradient increases as the distance between vortex cores decreases, i.e. as the initial spacing $s$ decreases. The present results confirm this model of vortex array decay.

\section{Modelling the Effects of Vortex Generator Spacing on Shed Vortex Circulation}

The effect of vortex generator proximity on shed vortex strength (or circulation) was first noted by Brown et al. ${ }^{8}$ In Brown's study, the array consisted of pairs of

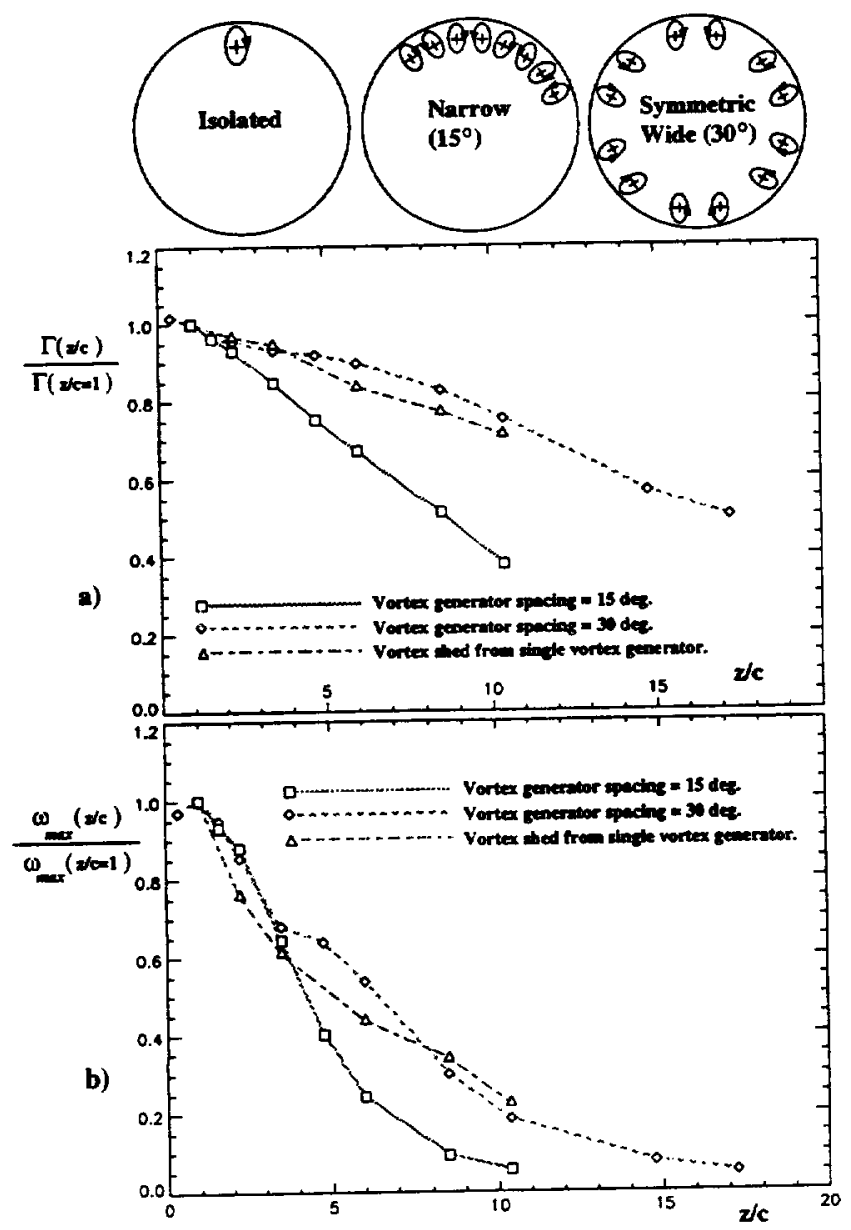

Figure 9 Axial decay of circulation and peak vorticity. vortex generators. Each pair was composed of two airfoil sections in close proximity, set to produce a downflow pair of embedded vortices. The spacing between neighboring pairs was much larger than the spacing between the vortex generators in each pair. The authors noted that when the distance between the vortex generators in each pair was decreased below a certain critical value the shed vortex strength decreased. This was termed "lift interference", but the effect was not quantified or analyzed. As discussed earlier, the results of this study indicate an opposite reaction; that is, counter-rotating vortices shed from an array of equally-spaced vortex generators are strengthened as the spacing decreases. We also note that the dominant vortex flow formation in this study consists of pairs of upflow vortices.

As the spacing between vortex generators decreases, regions of local flow acceleration in the vicinity of the vortex generator array intensify. This assumption forms the basis for the following analysis. Let $\Gamma_{i v}$ represent the circulation of a vortex shed from an isolated vortex generator. The circulation of a vortex shed from a vortex generator contained in an array of equal spacing $\Delta \theta_{b}$ is $\Gamma_{a v}$ :

$$
\Gamma_{a v}=\Gamma_{i v}+d \Gamma_{i v} .
$$

Dimensional analysis (using elements of inviscid airfoil theory) relates the circulation to the static pressure differential $\Delta P$ maintained about the airfoil:

$$
\Gamma_{i v} \approx \frac{c \Delta P}{\rho v_{c z}},
$$

where $\rho$ is fluid density. Thus we write:

$$
d \Gamma_{i v}=\frac{c d(\Delta P)}{\rho v_{c z}}
$$

Figure 10 diagrams a top view of an array of 4 equally

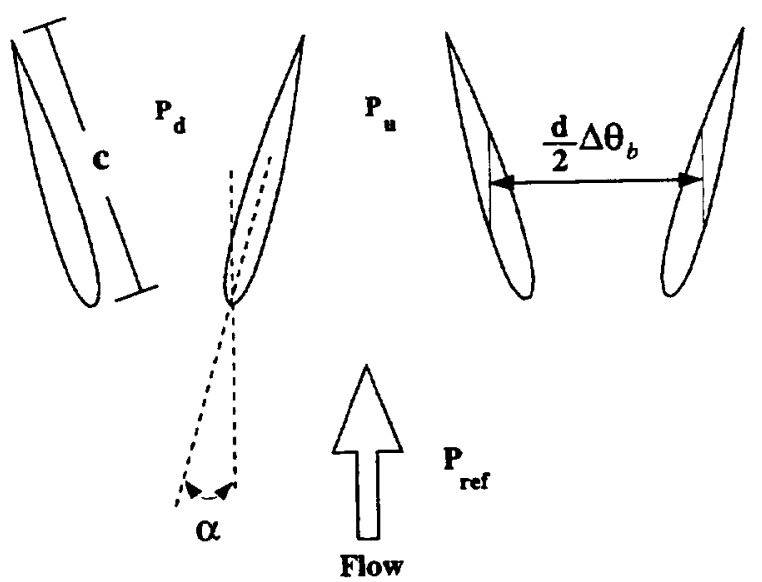

Figure 10 A top view of the vortex generator array.

spaced vortex generators similar to the formations considered in this study. The airstream moves from bottom to top in Figure 10. The two middle vortex generators create 
an upflow pair of vortices and the pair of vortex generators on either side of this array produce downflow pairs. Counter to what we might expect intuitively, the static pressure rises between the two middle vortex generators. To see that this is so, consider what occurs when the spacing is decreased to the point where the trailing edges meet. A region of stagnation pressure is established." Correspondingly, static pressure decreases between the vortex generator pairs on either side of the array. Thus the effect of neighboring vortex generators is to promote an enhanced pressure differential $d(\Delta P)=\Delta P_{a}=P_{u}-P_{d}$ about the chordlength of the vortex generators. This pressure differential is approximated inviscidly by assuming a mass flux balance between the leading and trailing edges of the array such that the axial velocity at the array trailing edge is (nominally) the core value, $v_{c z}$. Thus:

$$
\Delta P_{a}=\frac{\rho v_{c z}^{2}}{2}\left\{\frac{\left(\beta_{+}\right)^{4}-\left(\beta_{-}\right)^{4}}{\left(\beta_{-}\right)^{2}\left(\beta_{+}\right)^{2}}\right\}
$$

where:

$$
\begin{aligned}
& \beta_{-}=\frac{d}{2} \Delta \theta_{b}-c \sin \alpha, \\
& \beta_{+}=\frac{d}{2} \Delta \theta_{b}+c \sin \alpha
\end{aligned}
$$

and so:

$$
d \Gamma_{i v}=\kappa_{a} \frac{v_{c 2} c}{2}\left\{\frac{\left(\beta_{+}\right)^{4}-\left(\beta_{-}\right)^{4}}{\left(\beta_{-}\right)^{2}\left(\beta_{+}\right)^{2}}\right\}
$$

The resulting pressure differential is likely to be much less severe than that predicted by Eq. (10), due to the finite aspect ratio of the vortex generators and the resulting three-dimensional structure of the flowfield. The non-dimensional constant $\kappa_{a}$ is introduced in Eq. (12) to account for this. Upon comparison to the circulation data collected in the three spacing test cases (at $z / c=1.000$ ) we find $\kappa_{a} \approx 0.0274$. Following Eq. (12) we construct a plot of $d \Gamma_{i v}$ versus $\Delta \theta_{b}$. This is illustrated in Figure 11 .

- Such a pressure field occurs in the vicinity of a vortex generator device known as a "Wheeler Wishbone". 23 Studies $^{24,13}$ indicate that a strong pair of upflow vortices are shed from such devices.

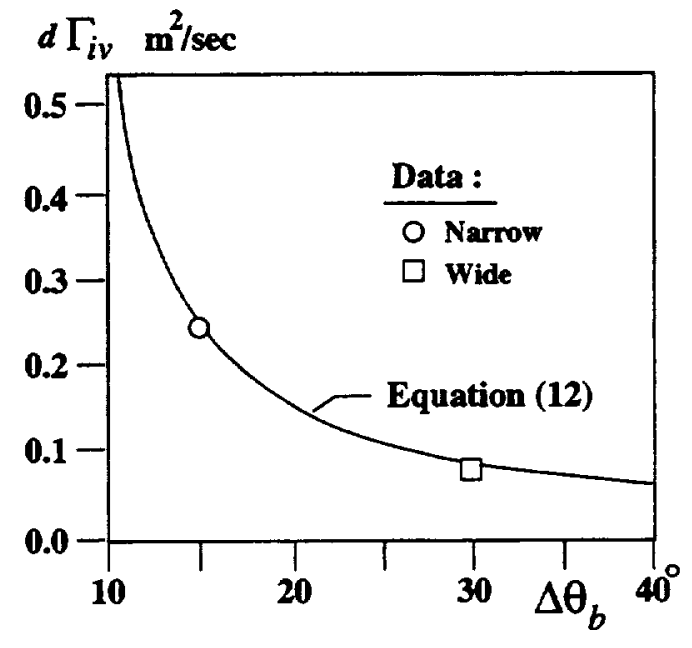

Figure 11 Circulation increase versus vortex generator spacing.

Summary

An experimental study is conducted to examine the crossplane flow structure and axial decay of counter-rotating longitudinal vortices shed from an array of equally-spaced symmetric airfoil vortex generators mounted on the surface of a straight pipe. The airfoils have a NACA 0012 cross-sectional profile and are mounted at an angle-of-attack $\alpha= \pm 16^{\circ}$. Impinging flow conditions are subsonic, incompressible, and the turbulent boundary layer thickness to pipe diameter ratio is approximately 0.09 . The vortex generator span to boundary layer thickness ratio is approximately 0.60 . Vortex structure and decay are quantified using crossplane circulation and peak streamwise vorticity. The primary goal of this study is to examine the effect of spacing between the parent vortex generators. Crossplane velocity measurements and derived streamwise vorticity fields are presented for an array of vortices shed from vortex generators spaced 15 degrees apart. Initial structure (recorded at a crossplane 1 chordlength downstream of the array trailing edges) and axial decay results are compared against similar results for an array of vortex generators spaced 30 degrees apart, and an isolated vortex shed from a single vortex generator under identical impinging flow conditions. When the spacing between vortex generators is decreased the circulation and peak vorticity of the shed vortices increases. Analysis indicates this strengthening results from regions of fluid acceleration and deceleration in the vicinity of the vortex generator array. Decreased spacing between the counter-rotating vortices also produces increased axial decay rates of circulation and peak vorticity.

\section{Acknowledgments}

This work was supported by the National Research Council and NASA Lewis. The authors would like to 
thank Dr. Warren Hingst, William Darby, Bob Ehrbar, Robert Gronski, Charles Wasserbauer, Bernie Anderson, Jeffry Foster, Arthur Sprungle, Julianne Dudek, and Dr. Frank Tipler for their dedicated assistance and belpful insights.

\section{References}

'Grose, R. M. and Taylor, H. D., "Theoretical and Experimental Investigation of Various Types of Vortex Generators," United Aircraft Corporation Research Department Report R-15362-5, East Hartford, CT, Mar. 1954.

${ }^{2}$ Schubauer, G. B. and Spangenburg, W. G., "Forced Mixing in Boundary Layers," Journal of Fluid Mechanics, Vol. 8, 1960, pp. 10-31.

${ }^{3}$ Spangler, J. G. and Wells, C. S., "Effects of Spiral Longitudinal Vortices on Turbulent Boundary Layer Skin Friction," NASA CR 145, 1964.

${ }^{4}$ Taylor, H. D., "Retractable Vortex Generators," United Aircraft Corporation Research Department Report M15355-3, 1950.

${ }^{5}$ Pearcy, H. H., "Shock-Induced Separation and its Prevention by Design and Boundary Layer Control," Boundary Layer and Flow Control, Vol. 2, edited by G. V. Lachmann, Pergamon Press, New York, 1961, pp. 11661344.

${ }^{6}$ Reichert, B. A. and Wendt, B. J., "Improving Curved Subsonic Diffuser Performance with Vortex Generators," AIAA Joumal, Vol. 34, Jan. 1996, pp. 65-72.

${ }^{7}$ Anderson, B. H. and Gibb, J., "Vortex Generator Installation Studies on Steady State and Dynamic Distortion," AIAA Paper 96-3279, July 1996.

${ }^{8}$ Brown, A. C., Nawrocki, H. F., and Paley, P. N., "Subsonic Diffusers Designed Integrally with Vortex Generators," Journal of Aircraft, Vol. 5, 1968, pp. 221229.

${ }^{9}$ Wendt, B. J. and Dudek, J. C., "A ComputationalExperimental Development of Vortex Generator Use for a Transitioning S-Diffuser," Paper accepted for presentation at the ASME 1996 International Mechanical Engineering Congress and Exhibit, Atlanta, Georgia, November 1722, 1996.

${ }^{10}$ Levy, R., Briley, W. R., and McDonald, H., "Viscous Primary/Secondary Flow Analysis for Use with Nonorthogonal Coordinate Systems," AIAA Paper 830556, Jan. 1983.

11 Wendt, B. J., Reichert, B. A., and Foster, J. D., "The Decay of Longitudinal Vortices Shed from Airfoil Vortex Generators," AIAA Paper 95-1797, June 1995.
${ }^{12}$ Westphal, R. V., Pauley, W. R., and Eaton, J. K., "Interaction Between a Vortex and a Turbulent Boundary Layer-Part 1: Mean Flow Evolution and Turbulence Properties," NASA TM 88361, Jan. 1987.

${ }^{13}$ Wendt, B. J. and Hingst, W. R., "Flow Structure in the Wake of a Wishbone Vortex Generator," AIAA Journal, Vol. 32, Nov. 1994, pp. 2234-2240.

${ }^{14}$ Eibeck, P. A. and Eaton, J. K., "An Experimental Investigation of the Heat-Transfer Effects of a Longitudinal Vortex Embedded in a Turbulent Boundary Layer," Stanford University Tech. Rep. MD-48, Stanford, CA, Nov. 1985.

${ }^{15}$ Pauley, W. R. and Eaton, J. K., "The Fluid Dynamics and Heat Transfer Effects of Streamwise Vortices Embedded in a Turbulent Boundary Layer," Stanford University Tech. Rep. MD-51, Stanford, CA, Aug. 1988.

${ }^{16}$ Wendt, B. J., Greber, I., and Hingst, W. R., "The Structure and Development of Streamwise Vortex Arrays Embedded in a Turbulent Boundary Layer," AJAA Paper 92-0551, Jan. 1992.

${ }^{17} \mathrm{Kim}$, W. J. and Patel, V. C., "Longitudinal Vortices in a Turbulent Boundary Layer Along a Curved Wall," Paper presented at the 19th Symposium on Naval Hydrodynamics, Seoul, Korea, August, 1992.

${ }^{18}$ Wendt, B. J. and Reichert, B. A., "The Modelling of Symmetric Airfoil Vortex Generators," AIAA Paper 960807, Jan. 1996.

${ }^{19}$ Porro, A. R., Hingst, W. R., Wasserbauer, C. A., and Andrews, T. B., "The NASA Lewis Research Center Internal Fluid Mechanics Facility," NASA TM 105187, Sept. 1991.

${ }^{20}$ Zilliac, G. G., "Modelling, Calibration, and Error Analysis of Seven-Hole Probes," Experiments in Fluids, Vol. 14, 1993, pp. 104-120.

${ }^{21}$ Moffat, R. J., "Contributions to the Theory of SingleSample Uncertainty Analysis," Transactions of the ASME, Vol. 104, June 1982, pp. 250-258.

${ }^{22}$ Wendt, B. J., Greber, I., and Hingst, W. R., "The Structure and Development of Streamwise Vortex Arrays Embedded in a Turbulent Boundary Layer," ALAA Journal, Vol. 31, Feb. 1993, pp. 319-325.

${ }^{23}$ Wheeler, G. O., "Means for Maintaining Attached Flow of a Flowing Medium," United States Patent 4,455,045 , June, 1984.

${ }^{24}$ Lin, J. C., Selby, G. V., and Howard, F. G., "Exploratory Study of Vortex-Generating Devices for Turbulent Flow Separation Control," AIAA Paper 91-0042, Jan. 1991. 
Public reporting bunden for this collection of information ts estimated to average thour per response, inctuding the time for reviewing instructions, searching existing data sources. gathering and maintaining the deta meded. and completing and reviowing the collection of informetion. Send comrnents regarding this burden extimate or any other aspact of this collection of informetion, including sugaestions for reducing this burden, to Washington Headquaners Services. Directorate lor Information Operations and Repons. 1215 Jefferson Devis Highway, Sulte 1204. Avington. VA 22202-4302, and to the Office of Management and Budget, Papenwork Peduction Propat (0704-0189), Washington, DC 20503.

\begin{tabular}{|l|l|l|}
\hline 1. AGEMCY USE ONLY (Leave blank) & $\begin{array}{c}\text { 2. REPORT DATE } \\
\text { November } 1996\end{array}$ & $\begin{array}{r}\text { 3. AEPOFT TYPE AND DATES COVEAED } \\
\text { Final Contractor Report }\end{array}$ \\
\hline
\end{tabular}

\section{TILE ANO SUBTILE}

Spanwise Spacing Effects on the Initial Structure and Decay of Axial Vortices

6. AUTHOR(S)

Bruce J. Wendt and Bruce A. Reichert

7. PERFORIMNG ORGANIZATION MAME(S) AND ADDAESS(ES)

Modern Technologies Corporation

7530 Lucerne Drive

Islander Two, Suite 206

Middleburg Heights, Ohio 44130

9. SPONSORINGMONTORING AGENCY NAME(S) AND ADDRESS(ES)

National Aeronautics and Space Administration

Lewis Research Center

Cleveland, Ohio 44135-3191
5. FUNDING NUMBERS

WU-523-36-13

C-NAS3-27377

8. PERFofIMING ORGANIZATION REPORT NUMBER

E-10512

10. SPONSORUNGMONITOPANG AGENCY REPORT NUMBER

NASA CR-198544

11. SUPPLEMENTARY NOTES

Bruce J. Wendt, Modem Technologies Corporation and Bruce A. Reichert, Kansas State University, Manhattan, Kansas 66506. Project Manager, John Abbott, Internal Fluid Mechanics Division, NASA Lewis Research Center, organization code 2600 , (216) 433-3607.

12a. DISTRIBUTONAVAILABILTTY STATEMENT

Unclassified - Unlimited

Subject Category 02

This publication is available from the NASA Center for AeroSpace Information, (301) 621-0390.

13. ABSTRACT (Maximem 200 words)

The initial structure and axial decay of an array of streamwise vortices embedded in a turbulent pipe boundary layer is experimentally investigated. The vortices are shed in counter-rotating fashion from an array of equally-spaced symmetric airfoil vortex generators. Vortex structure is quantified in terms of crossplane circulation and peak streamwise vorticity. Flow conditions are subsonic and incompressible. The focus of this study is on the effect of the initial spacing between the parent vortex generators. Arrays with vortex generators spaced at 15 and 30 degrees apart are considered. When the spacing between vortex generators is decreased the circulation and peak vorticity of the shed vortices increases. Analysis indicates this strengthening results from regions of fluid acceleration in the vicinity of the vortex generator array. Decreased spacing between the constituent vortices also produces increased rates of circulation and peak vorticity decay.

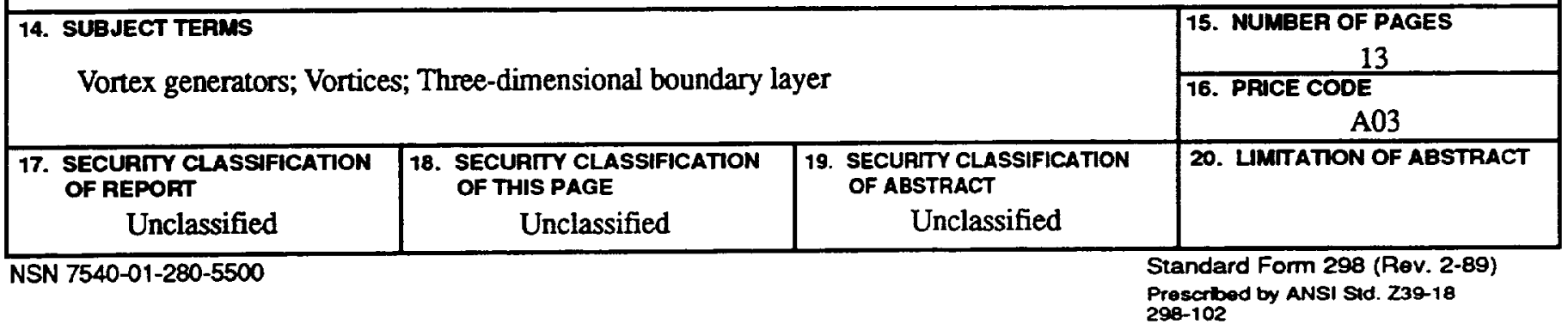

